\title{
Microwave-assisted extraction of phycobiliproteins from Porphyridium purpureum
} \author{
Joguet Nicolas ${ }^{1}$, Kaas Raymond ${ }^{2}$, Cadoret Jean-Paul ${ }^{2}$, Picot Laurent ${ }^{1, *}$ \\ ${ }^{1}$ UMRi CNRS 7266 LIENSs University of La Rochelle, 17042, La Rochelle, France \\ 2 IFREMER Laboratoire BRM/PBA, Rue de l'lle d'Yeu, 44311, Nantes, France \\ * Corresponding author : Laurent Picot, email address : Ipicot@univ-Ir.fr
}

Juin Camille ${ }^{1}$, Cherouvrier Jean-René ${ }^{1}$, Thiéry Valérie ${ }^{1}$, Gagez Anne-Laure ${ }^{1}$, Bérard Jean-Baptiste ${ }^{2}$,

\begin{abstract}
:
In the present study, microwave-assisted extraction was first employed to extract the phycobiliproteins of Porphyridium purpureum $(P p)$. Freeze-dried Pp cells were subjected to microwave-assisted extraction (MAE) to extract phycoerythin (PE), phycocyanin (PC), and allophycocyanin (APC). MAE combined reproducibility and high extraction yields and allowed a 180- to 1,080-fold reduction of the extraction time compared to a conventional soaking process. The maximal PE extraction yield was obtained after 10-s MAE at $40 \mathrm{~A}$ degrees $\mathrm{C}$, and PE was thermally damaged at temperatures higher than $40 \mathrm{~A}$ degrees $C$. In contrast, a flash irradiation for $10 \mathrm{~s}$ at 100 A degrees $C$ was the best process to efficiently extract PC and APC, as it combined a high temperature necessary to extract them from the thylakoid membrane to a short exposure to thermal denaturation. The extraction order of the three phycobiliproteins was coherent with the structure of $\mathrm{Pp}$ phycobilisomes. Moreover, the absorption and fluorescence properties of MAE extracted phycobiliproteins were stable for several months after the microwave treatment. Scanning electron microscopy indicated that MAE at $100 \mathrm{~A}$ degrees $\mathrm{C}$ induced major changes in the $P p$ cell morphology, including fusion of the exopolysaccharidic cell walls and cytoplasmic membranes of adjacent cells. As a conclusion, MAE is a fast and high yield process efficient to extract and pre-purify phycobiliproteins, even from microalgae containing a thick exopolysaccharidic cell wall.
\end{abstract}

\section{Highlights}

- Phycobiliproteins are high value fluorescent microalgae pigments. Most phycobiliprotein extraction processes imply the use of ionic buffers or enzymes. Porphyridium purpureum phycobiliproteins can be efficiently extracted using MAE. MAE gives high extraction yields and reduces extraction time. - Absorption and fluorescence properties of extracted pigments are not altered by MAE.

Keywords: Allophycocyanin, MAE, Microalgae, Microwave, Phycobiliprotein, Phycocyanin, Phycoerythrin, Porphyridium, Thylakoid 


\section{Introduction}

Phycobiliproteins (PBP) are hydrophilic $\alpha \beta$ heterodimeric proteins constituting the major light-harvesting pigments of cyanobacteria, red algae, glaucocystophytes, and cryptophytes [1]. Both the $\alpha$ and $\beta$-subunits consist of an open-chain tetrapyrrole constituting the chromophore, linked to an $\mathrm{N}$-terminal proteic extension involved in the subunit aggregation to $\alpha \beta$ protomers. The $\alpha \beta$ protomers (referred to as "monomer") can further aggregate to form triangular-shaped trimers (heterohexamers) and hexamers (heterododecamers), that constitute the building blocks of phycobilisomes (PBS), the light harvesting antennae anchored in the thylakoid membranes [1]. In Porphyridium purpureum (Pp), PBS mostly contain PE, PC and APC (the three PBP) linked to colorless proteins associated to PE or attaching the PBS core to the thylakoid membranes [2]. PE, PC and APC are spatially organized to transfer energy from higher energy chromophores located in the distal part of the PBS (PE) to the lower energic ones (PC and APC forming the PBS core) [1]. Because of their unique structural characteristics [1], PBP have intrinsic fluorescence properties which make them highly sensitive fluorophores for various fluorescence based techniques such as immunofluorescence, FACS and fluorimetric microplate assays [3, 4]. PBP are also used in cosmetics [5], nutraceuticals [6], and in oceanography studies as chemotaxonomic markers [1, 7, 8]. Furthermore, recent studies demonstrated that they exert a direct cytotoxicity in cancer cells and potentiate the effect of chemotherapeutic drugs [9-13]. Various processes were thus developed to extract and purify PBP from microalgae and seaweeds. Because phycobilisomes are strongly anchored in the thylakoid membrane, and protected from extraction solvents by a thick exopolysaccharidic cell wall, the first extraction processes used drastic techniques such as mechanical grinding using a French press, in high-ionic strength buffers to prevent phycobilisomes dissociation [1]. Alternative processes were proposed, such as the use of enzymes to hydrolyze the algal cell walls [14] and the use of sucrose density centrifugation to purify phycobilisomes combined to ammonium sulfate fractionation and precipitation, centrifugation, dialysis, isoelectric focusing, ion exchange chromatography and/or gel permeation to purify the chromoproteins [14-20]. Although they allow the purification of PBP with high purity, according to the absorbance ratio $A_{\mathrm{PBP}} / A_{280}$, these processes are time, money and solvent consuming and involve tedious steps that can eventually decrease extraction yields. Microwave-assisted extraction (MAE) is an alternative innovative technology that is used to extract pigments [21, 22], lipids and bioactive molecules from plants, spices, seaweeds and microalgae [23, 24]. The main advantages of MAE are a significant reduction in extraction time, reduced solvent consumption, and high extraction yields that can be increased from 50 to $500 \%$ compared to conventional extraction processes [25]. MAE is not restricted to thermoresistant molecules, as the shortened extraction time allows the non-damaging extraction of thermolabile constituents such as human proteins [26], plant polyphenols [27-29], essential oils [30, 31], or microalgae pigments [21]. MAE can also be developed with eco-friendly solvents [32] and be performed at low temperature under vacuum (VMAE) [28] or without the addition of external solvent (the molecules are then solvated in the water sample and collected in a cold trap). We thus hypothesized that MAE was a high performance process for the extraction of PBP from marine microalgae, and selected Porphyridium purpureum as a model species to perform the MAE of phycocyanin (PC), phycoerythrin (PE) and allophycocyanin (APC). The MAE performance was compared to the conventional soaking process on the basis of extraction yields, purity of the extracted PBP, and extraction duration, after optimization of MAE parameters. 


\section{Material and methods}

\subsection{Microalgae}

Porphyridium purpureum CCAP 1380.3 (bangiophyceae, rhodophyte) was selected as it contains three PBP (PE, PC and APC) in high amounts $[2,33] . P p$ is one of the most used species to purify PBP, and its exopolysaccharidic cell wall constitutes a mechanical barrier that limits pigments extraction using conventional soaking processes [34, 35].

\subsection{Microalgae culture, harvest and freeze-drying}

$P p$ was grown at $120 \mu \mathrm{mol} \mathrm{m} \mathrm{s}^{-2}$ irradiance to achieve a good compromise between growth , biomass and production of PBP [33]. Cells were grown in four units of $50 \mathrm{~L}$ column photobioreactors with $35 \%$ salinity seawater enriched by Walne medium [36]. Batch cultures were maintained at $20^{\circ} \mathrm{C}$ under continuous light provided by fluorescent lamps (Philips TLD $58 \mathrm{~W} 865)$ and bubbled with $0.22-\mu \mathrm{m}$ filtered air containing $3 \% \mathrm{CO}_{2}(\mathrm{v} / \mathrm{v})$. Microalgae were harvested after 12-16 days of growth and separated from the culture medium by a two-step process. First step used a clarifier separator (Clara 20, Alfa Laval Corporate AB, Sweden) at $100 \mathrm{~L} \cdot \mathrm{h}^{-1}, 9000 \mathrm{~g}$, room temperature. Step two used a soft centrifugation at $4000 \mathrm{~g}, 20 \mathrm{mn}$, $4^{\circ} \mathrm{C}$ to separate the slurry. Algal paste was freeze-dried at $-55^{\circ} \mathrm{C}$ and $\mathrm{P}<1 \mathrm{hPa}$, on a freezedryer equipped with a HetoLyoPro 3000 condenser and a Heto cooling trap (Thermo, France) to express extraction yields in micrograms of pigments per $\mathrm{mg}$ of dry microalgae.

\subsection{PBP extraction}

MAE was performed using a Biotage initiator microwave reactor (Figure 1.), at atmospheric pressure and in deionized water as PBP are hydrophilic pigments. Because PBP are thermosensitive proteins [37], the extraction temperature and exposure duration to high temperatures are two critical parameters. Optimization of the MAE parameters aimed to efficiently destroy pigments extraction barriers ( $P p$ exopolysaccharidic cell wall and PBP anchoring in the thylakoid membrane) and obtain high extraction yields in a fast process, limiting the risk of thermal damage of the extracted PBP. MAE was thus performed from $40^{\circ} \mathrm{C}$ (lower temperature available in the Biotage reactor) to $120^{\circ} \mathrm{C}$, for durations ranging from $10 \mathrm{~s}$ (flash irradiation) to $5 \mathrm{~min}$. The solid-to-solvent ratio was constant and fixed to 20 $\mathrm{mg}$ freeze-dried $P p$ cells suspended in $7 \mathrm{ml}$ deionized water. MAE was performed in sealed microwave vials, in triplicate independent assays, under constant magnetic stirring (600 rpm). 


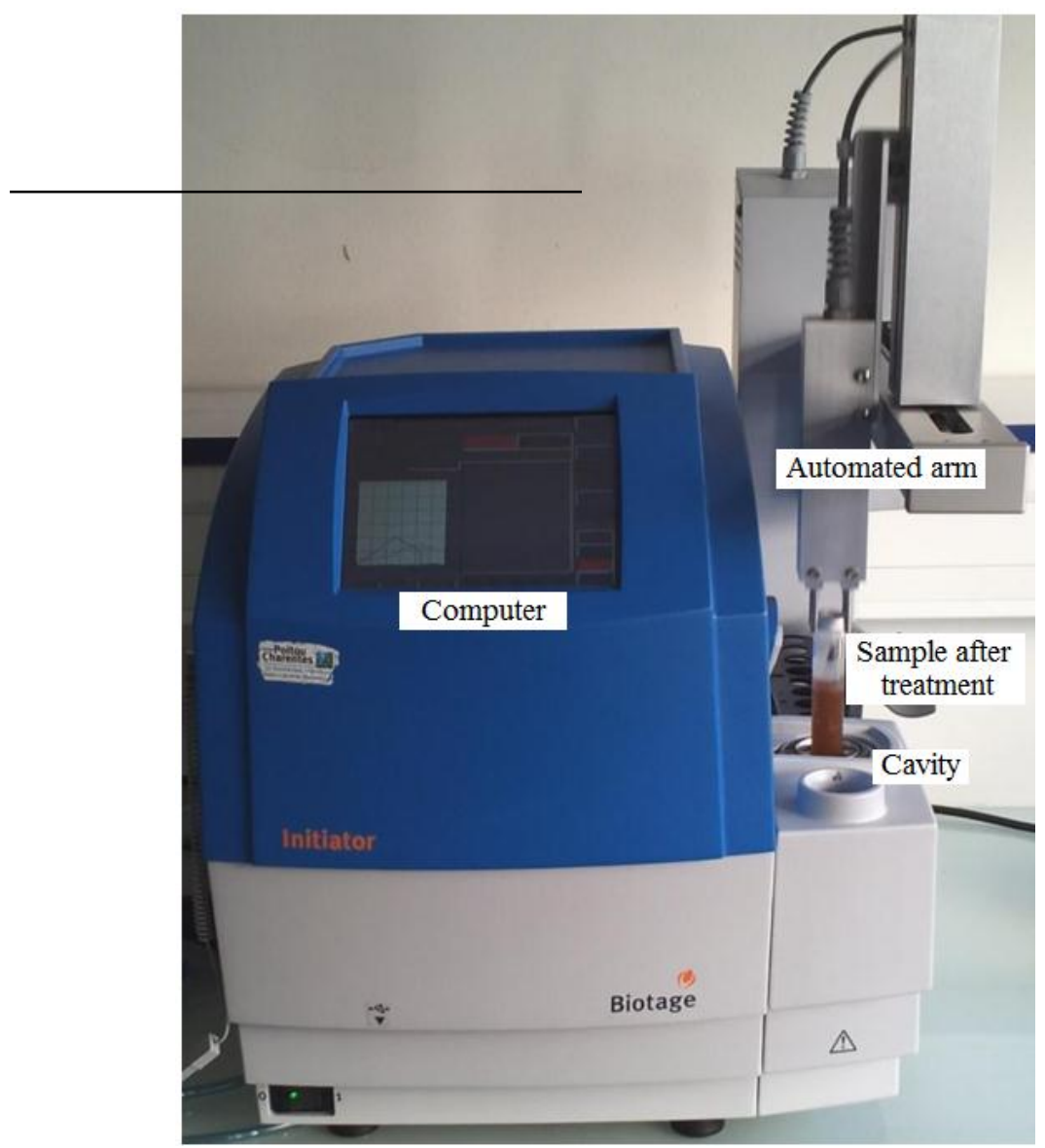

Figure 1. Photograph of the Biotage initiator microwave reactor after PBP extraction using the MAE process. Microwaves irradiation evokes an instantaneous and homogeneous heat transfer in the sample, inducing microalgal cell wall disruption and solid-liquid extraction of thylakoid pigments.

After MAE, extracts were centrifuged $\left(4500 \mathrm{~g}, 4^{\circ} \mathrm{C}, 5 \mathrm{~min}\right)$ to pellet cell debris and the supernatants were collected in brown vials for PBP dosage. For the absorbance and fluorescence stability study, PBP were stored in brown vials at $4^{\circ} \mathrm{C}$ before dosage. In order to quantify the reduction of extraction time offered by MAE, soaking extracts were also prepared using the same time, temperature and solvent-to-solid ratios as MAE.

\subsection{PBP absorbance}

Absorbance of the pigments solutions was recorded at 280, 545, 565, 620 and $650 \mathrm{~nm}$ on a Perkin-Elmer lambda $650 \mathrm{UV}$-visible spectrophotometer. The PE, PC and APC massic concentrations (g.L $\mathrm{L}^{-1}$ ) were calculated using the following equations, according to [38-40].

$$
\begin{aligned}
& {[\mathrm{PC}]=\frac{\mathrm{OD} 620-\left(\frac{\mathrm{APC6} 20}{\mathrm{APC650}}\right) * \mathrm{OD} 650}{\mathrm{PC620}-(\mathrm{APC620} * \mathrm{PC} 650) / \mathrm{APC} 650}} \\
& {[\mathrm{APC}]=\frac{\mathrm{OD} 650-\left(\frac{\mathrm{PC} 650}{\mathrm{PC620}}\right) * \mathrm{OD} 620}{\mathrm{APC650}-(\mathrm{APC620} * \mathrm{PC} 650) / \mathrm{PC} 620}}
\end{aligned}
$$




$$
[\mathrm{PE}]=\frac{\mathrm{OD} 545-[\mathrm{PC}] * \mathrm{PC} 545-[\mathrm{APC}] * \mathrm{APC} 545}{\mathrm{PE} 545}
$$

The massic extinction coefficients of the 3 PBP were measured with standards solutions (Table 1) and used to simplify the above three equations to (4), (5) and (6) respectively.

\begin{tabular}{llll}
\multicolumn{1}{c}{$\left.\mathbf{L . g}^{\mathbf{- 1}} \cdot \mathbf{c m} \mathbf{- 1}^{\mathbf{1}}\right)$} & OD $545 \mathrm{~nm}$ & OD 620 nm & OD 650 nm \\
\hline PC & 1.26 & 3.69 & 0.75 \\
PE & 5.73 & - & - \\
APC & 0.62 & 3.99 & 6.39
\end{tabular}

Table 1. Massic extinction coefficients of standard phycocyanin, phycoerythrin and allophycocyanin.

$$
\begin{aligned}
& {[\mathrm{PC}]=\frac{(\mathrm{OD} 620-0.62 * \mathrm{OD} 650)}{3.22}} \\
& {[\mathrm{APC}]=\frac{(\mathrm{OD} 650-0.20 * \mathrm{OD} 620)}{5.73}} \\
& {[\mathrm{PE}]=\frac{(\mathrm{OD} 545-1.26 *[\mathrm{PC}]-0.615 *[\mathrm{APC}]}{5.53}}
\end{aligned}
$$

\subsection{PBP fluorescence}

The fluorescence spectrum of extracted PBP was recorded using a Hitachi F-2500 spectrofluorimeter. Fluorescence was measured from 200 to $800 \mathrm{~nm}\left(1500 \mathrm{~nm} . \mathrm{min}^{-1}\right.$, slit 2.5 $\mathrm{nm}$ ) after excitation at $488 \mathrm{~nm}$ for PE, $320 \mathrm{~nm}$ for PC and $330 \mathrm{~nm}$ for APC.

\subsection{SDS-PAGE of MAE extracted PBP}

Ten microliters of MAE extracts or PBP standards were mixed with $5 \mu \mathrm{L}$ loading buffer consisting in Tris $\mathrm{HCl} 50 \mathrm{mM}$ pH 6.8, Glycerol 10\%, SDS $2.5 \%$, Bromophenol blue 0.002 $\%$, without $\beta$-mercaptoethanol and at ambient temperature. PBP were then separated at $50 \mathrm{~V}$ for $15 \mathrm{~min}$ and $150 \mathrm{~V}$ for $75 \mathrm{~min}$ on a Mini-protean TGX $12 \%$ gel using a Bio-Rad Power Pack apparatus (Bio-Rad, France). Standard PBP were obtained from Sigma-Aldrich France and consisted, according to the manufacturer, in phycocyanin from Spirulina platensis (MW of the native protein $=112 \mathrm{KDa})$, synthesized allophycocyanin $(\mathrm{MW}$ of the native protein $=$ $104 \mathrm{KDa})$ and phycoerythrin from $P p(\mathrm{MW}$ of the native protein $=240 \mathrm{KDa})$. The prestained PageRuler Plus protein ladder (10 - $250 \mathrm{KDa}$, Thermo, France) was used as molecular weight marker. 


\subsection{Scanning electron microscopy (SEM) observation of $P p$ cells}

$P p$ cells were freeze-dried before or after MAE, placed on a conductive double layer carbon support and examined by SEM using a Philips-FEI Quanta 200 ESEM/FEG microscope (environmental mode) equipped with a FEG canon delivering 1 to $30 \mathrm{KV}$ beam current. The backscattered electron mode was used to get a contrast between inorganic salts and biological membranes.

\subsection{Statistical analysis}

The unpaired Student $t$ test ( $n=3$, triplicate independent extractions for each condition) was used to determine if MAE in optimized conditions significantly increased the extraction yield compared to soaking, and if the MAE temperature had a significant positive or negative effect on PE, PC and APC extraction yields for a selected extraction time.

\section{Results}

\subsection{Impact of MAE on Pp cell integrity}

SEM observation of $P p$ cells before or after MAE (Figure 2.) revealed that the freeze-dry process did not fully disrupt the cytoplasmic membrane, but only evoked a partial cell shrinkage and clustering. These data were coherent with our previous observations with Dunaliella tertiolecta (chlorophyte) and Cylindrotheca closterium (bacillariophyte) [21]. The presence of salts precipitates surrounding $P p$ freeze-dried cells was evident using the backscattered electron mode and revealed by the contrast between the dark organic material and the very bright salts cristals (Figure $2 \mathrm{~B}$ ). 

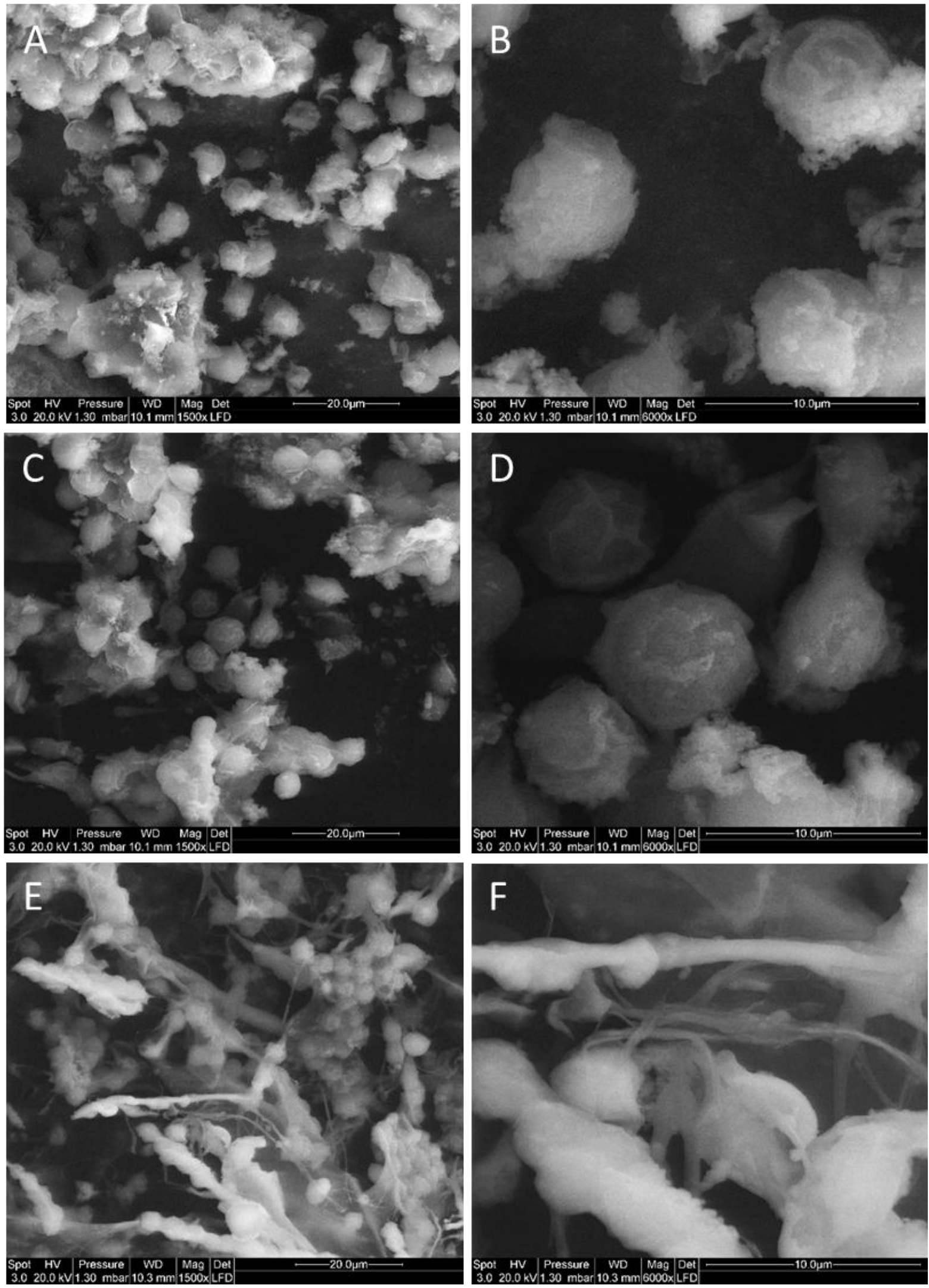

Figure 2. SEM observation of freeze-dried $P p$ cells before MAE extraction (A and B), after $10 \mathrm{~s}$ MAE at $40^{\circ} \mathrm{C}$ (C and $\left.\mathrm{D}\right)$, or after $30 \mathrm{~s}$ MAE at $100^{\circ} \mathrm{C}$ ( $\mathrm{E}$ and $\left.\mathrm{F}\right)$. Magnification: x 1500 (A, C and E); x 6000 (B, D and F). 
The presence of a thick exopolysaccharidic (EPS) cell wall surrounding $P p$ cells [34] probably participates to the conservation of the cell morphology during the freeze-dry process by limiting the risk of tearing the cytoplasmic membrane during ice cristals formation. MAE at $40^{\circ} \mathrm{c}$ had low influence on the cell morphology, although the $\mathrm{PE}$ extraction yields at $40^{\circ} \mathrm{C}$ (see below) evidenced that the inner content of $P p$ cells was accessible for the extraction solvent and that the PBS constituents were partially dissociated from the thylakoid membrane. Occasional fusion of the cell walls surrounding adjacent cells could be observed (Figure $2 \mathrm{D}$ ). MAE at $100^{\circ} \mathrm{C}$ evoked major changes of the $P p$ cells morphology, including systematic fusion of the cell walls in adjacent cells and appearance of long thin filaments that were identified as a mix of cytoplasmic membranes fused with the EPS cell walls (Figure 2 F). PC and APC extraction yields at $100^{\circ} \mathrm{C}$ (see below) confirmed that the thylakoids membranes were deeply disrupted and that the pigments extractability was not limited by the solvent diffusion across the cell wall and cytoplasmic membrane.

\subsection{MAE of phycoerythrin}

The maximal PE extraction yield $\left(73.7 \pm 2.3 \mu \mathrm{g} . \mathrm{mg}^{-1}\right)$ was obtained after $10 \mathrm{~s}$ irradiation at $40^{\circ} \mathrm{C}$ (Figure 3.). Increasing the irradiation time up to $5 \mathrm{~min}$ at $40^{\circ} \mathrm{C}$ had no impact on $\mathrm{PE}$ extraction yield, indicating that all extractable PE was recovered during the very first seconds of microwave irradiation, and confirming the previously reported thermostability of PE at $40^{\circ} \mathrm{C}[37]$.

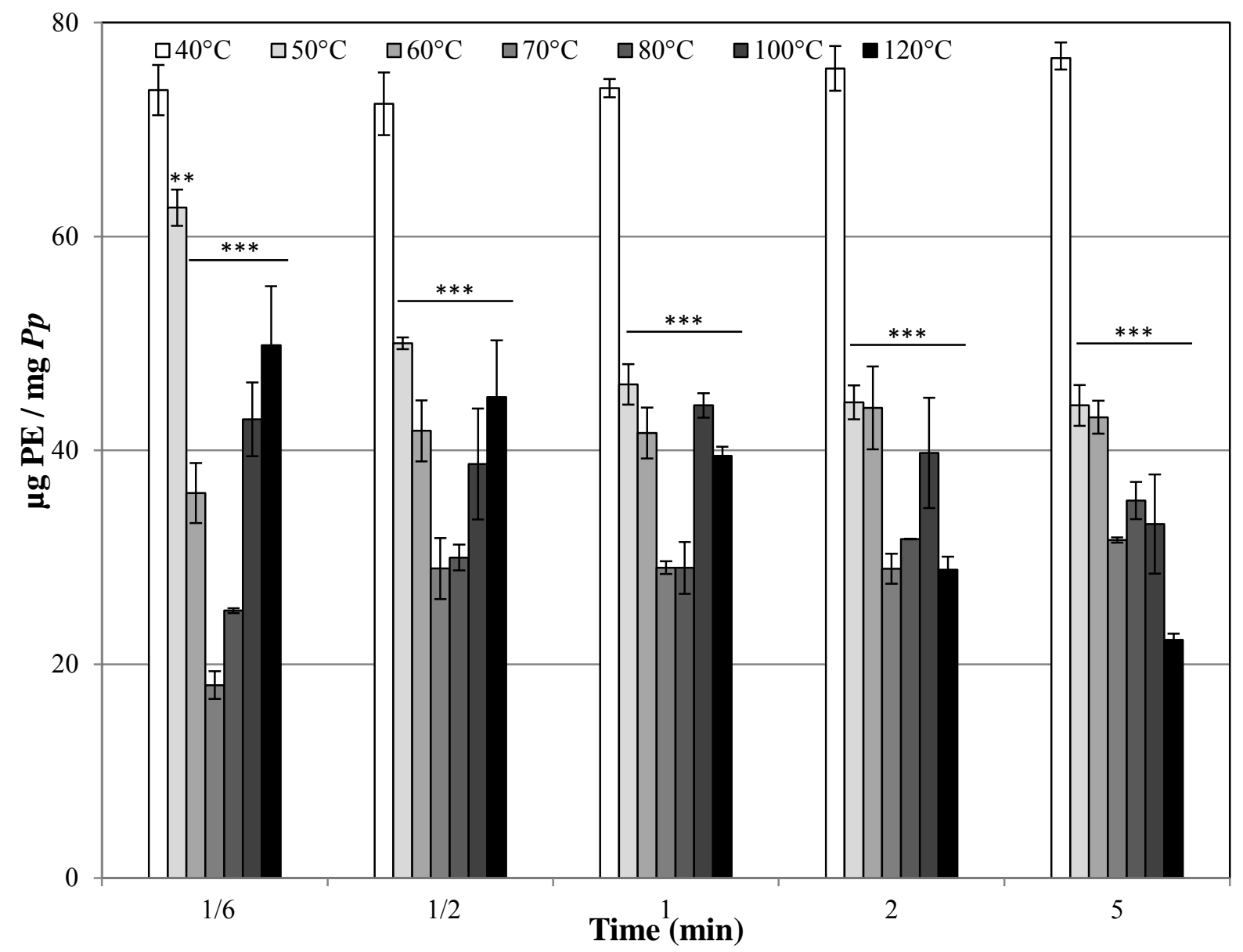


Figure 3. Extraction yields of $\mathrm{PE}$ after MAE in a large range of temperatures $\left(40-120^{\circ} \mathrm{C}\right)$. The maximal PE extraction yield was obtained after $10 \mathrm{~s}$ irradiation at $40^{\circ} \mathrm{C}$.

The PE maximal extraction yield was 54.6 fold superior to the value obtained by the aqueous two-phase extraction of $P p$ PE [41]. Although this high extraction yield indicates that MAE is a powerful extraction process compared to aqueous two-phase extraction, additional criteria including purity indexes, industrial scalability, and biomass cost have to be considered to define the global efficiency of the process. MAE gave a PE purity index of 2.2, while soaking and aqueous two-phase extraction respectively lead to purity indexes of 1.3 and 2.8 [42] to 4.3 [41] (Table 2). Considering that the current industrial microwaves reactors can contain up to 70 liters of sample [43], a theorical mass of $14.74 \mathrm{~g}$ of PE could be extracted in a single $10 \mathrm{~s}$ MAE from $200 \mathrm{~g}$ dry algae, according to our extraction yield and using our solid-liquid ratio. Observation of a maximal PE extraction yield at a relatively low temperature was coherent with the structural model proposed for the $P p$ PBS, in which PE, located at the distal part, is the most accessible of the three PBP. Using conventional soaking in water at $40^{\circ} \mathrm{C}, 60 \mathrm{~min}$ were necessary to get an equivalent extraction yield (data not shown), indicating that MAE allowed a 360 fold reduction of the extraction time. For an equivalent extraction time, the difference in PE extraction yields between MAE and soaking was extremely statistically significant $(p<0.0001$ using the Student unpaired $t$ test). PE corresponded to 83.6 to $84.1 \%$ of the total PBP massic content in the MAE extract, compared to 68 to $71 \%$ with the soaking process. Thus, MAE not only increased extraction yields but also increased the PE extraction selectivity, and this may be explained by the very short extraction time. Increasing the MAE temperature from $50^{\circ} \mathrm{C}$ to $100^{\circ} \mathrm{C}$ significantly decreased the extraction yield, confirming the thermal damage of $\mathrm{PE}$ at temperatures superior to $40^{\circ} \mathrm{C}$ (Figure 3.).

\subsection{MAE of phycocyanin and allophycocyanin}

The maximal extraction yields of $\mathrm{PC}$ and $\mathrm{APC}$ was twice to three times lower than that of PE, in accordance with the $\mathrm{PC} / \mathrm{APC} / \mathrm{PE}$ ratio described in the $\mathrm{Pp}$ PBS model. Irradiation at temperatures ranging from 40 to $80^{\circ} \mathrm{C}$ gave low extraction yields (5 to $10 \mu \mathrm{g} . \mathrm{mg}^{-1}$; Figures 4 . and 5.), that were explained by the weak extractability of the two pigments tightly bound to the thylakoid membrane compared to PE. The extraction yields significantly increased when the sample was treated at temperatures over $100^{\circ} \mathrm{C}$, and the morphological modifications of $P p$ cells at these temperatures confirmed that the pigments extraction barriers were strongly disrupted. However, increasing the irradiation time damaged the extracted PC and APC, as shown by the decrease of extraction yields (Figures 4. and 5.). As a conclusion, a flash irradiation at $100^{\circ} \mathrm{C}$ was the best MAE process to extract $\mathrm{PC}$ or $\mathrm{APC}$, as it combined a high energy, necessary to extract them from the thylakoid membranes and break the exopolysaccharidic cell wall, to a rapid treatment to limit the thermal damage of extracted pigments. 


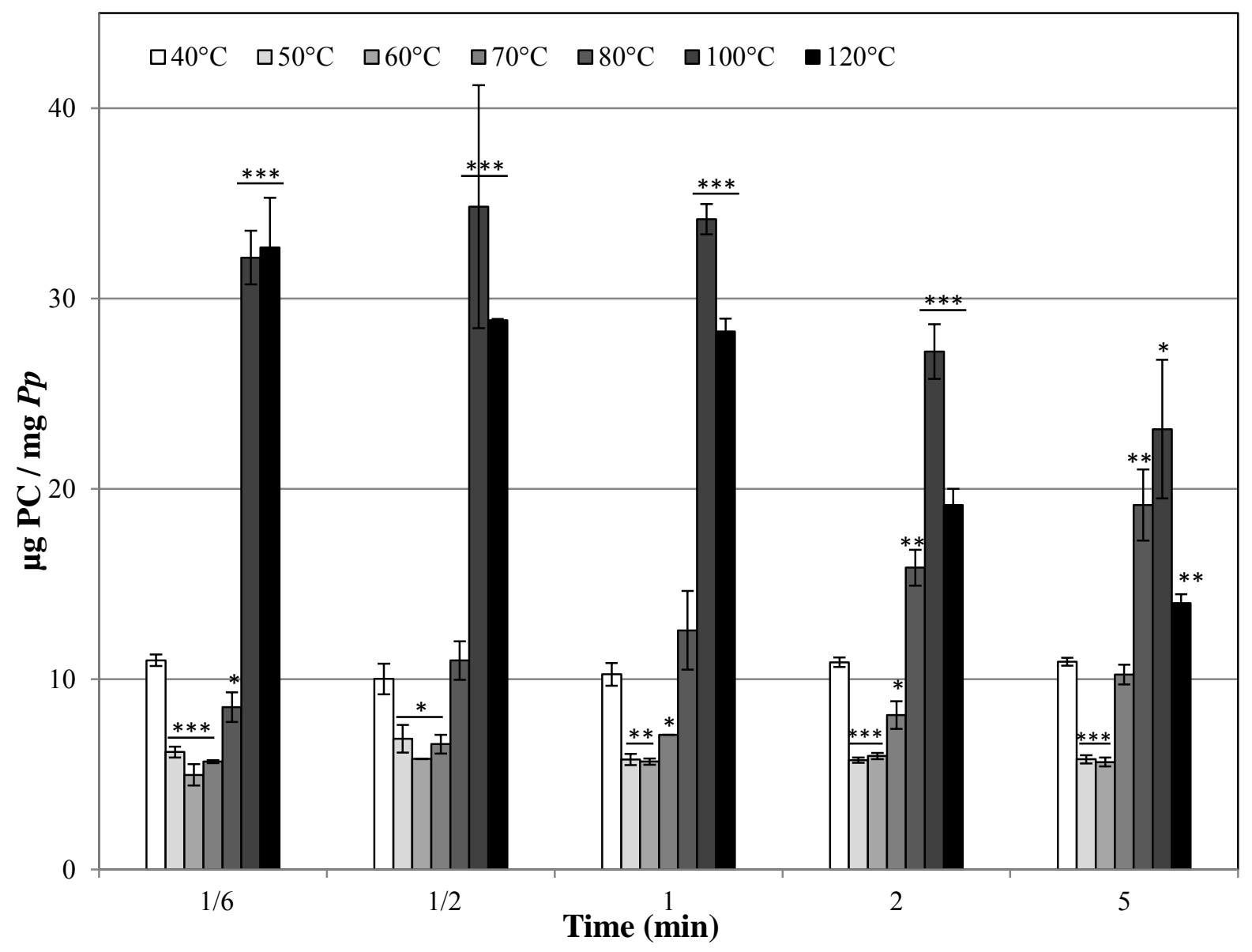

Figure 4. . Extraction yields of $\mathrm{PC}$ after MAE in a large range of temperatures $\left(40-120^{\circ} \mathrm{C}\right)$. The maximal extraction yield was obtained after a $10 \mathrm{~s}$ MAE irradiation at $100^{\circ} \mathrm{C}$. 


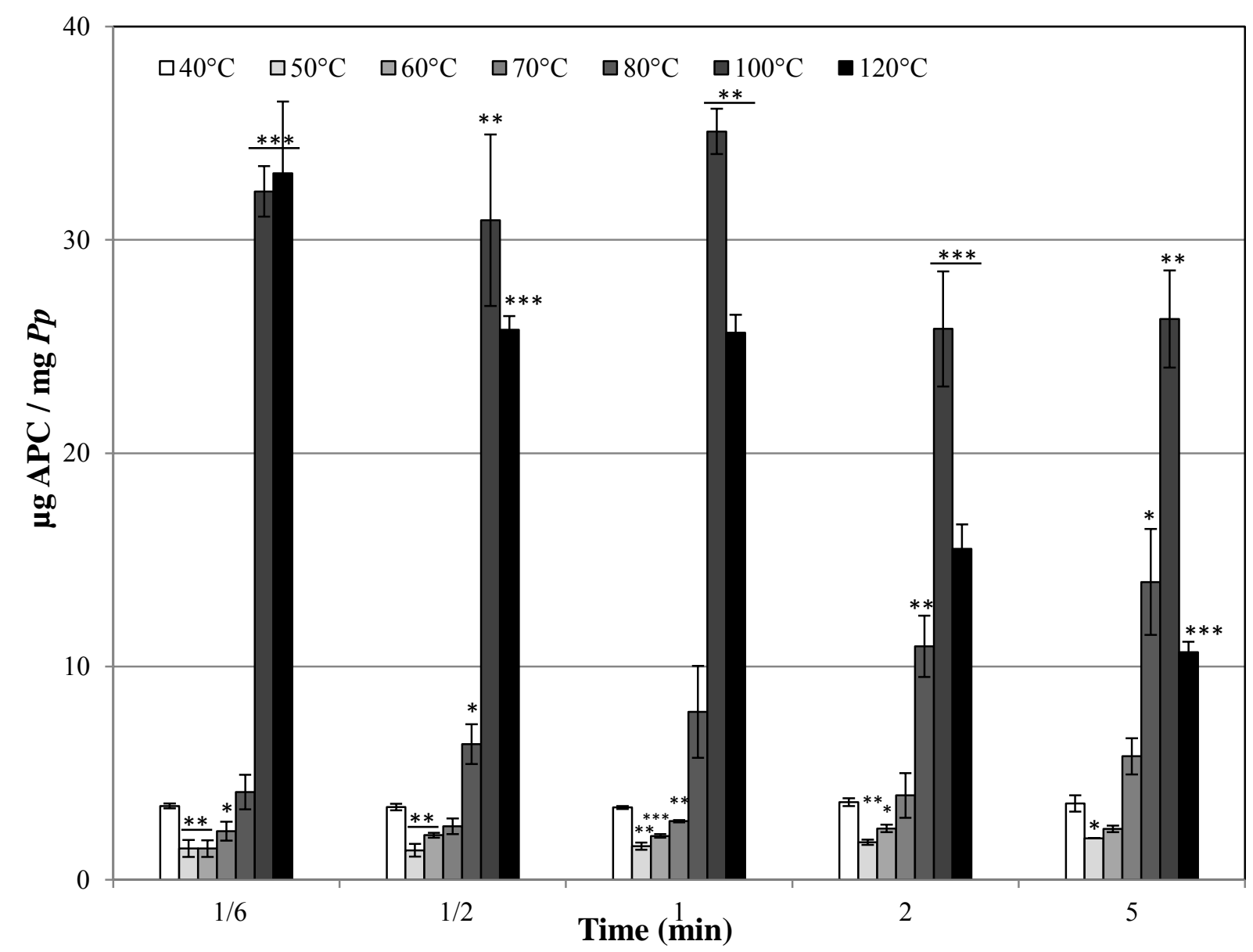

Figure 5. Extraction yields of APC after MAE in a large range of temperatures $\left(40-120^{\circ} \mathrm{C}\right)$. The highest extraction yield was obtained in $1 \mathrm{~min}$ at $100^{\circ} \mathrm{C}$.

The maximal PC extraction yield $\left(34.8 \pm 6.4 \mu \mathrm{g} \cdot \mathrm{mg}^{-1}\right)$ was obtained after $10 \mathrm{~s} \mathrm{MAE} \mathrm{at} 100^{\circ} \mathrm{C}$, and was equivalent to that measured after 60 to 180 min soaking (data not shown), indicating a 360 to 1080 fold reduction of the extraction time. For APC, the flash irradiation 10s at $100^{\circ} \mathrm{C}$ gave a high yield $\left(32.3 \pm 1.2 \mu \mathrm{g} \cdot \mathrm{mg}^{-1}\right)$ and $1 \mathrm{~min} \mathrm{MAE}$ at $100^{\circ} \mathrm{C}(180$ fold reduction of the extraction time compared to soaking) was necessary to obtain the highest extraction yield $\left(35.1 \pm 1.1 \mu \mathrm{g} \cdot \mathrm{mg}^{-1}\right)$ (Figure 5.), demonstrating that APC is more tightly bound to the thylakoid membrane than PC, in accordance with the $P p$ PBS model. In these optimized conditions, PC and APC respectively represented up to $33.3 \%$ and $30.9 \%$ of the total PBP present in the extract, and $\mathrm{PE}$ thermal damage at $100^{\circ} \mathrm{C}$ probably improved the selectivity of PC and APC extraction (Table 2).

Table 2. Performance of optimized MAE processes to extract and purify PBP from $P p$. The maximal extraction yields and purity indexes obtained by MAE are compared to the values obtained using soaking or previously reported processes.

\begin{tabular}{llcc}
\hline PBP & Process & $\begin{array}{l}\text { Extraction Yield } \\
\left(\mu \mathrm{g} \cdot \mathrm{mg}^{-1}\right)\end{array}$ & Purity \\
\hline PE & MAE $10 \mathrm{~s} 40^{\circ} \mathrm{C}$ & 73.7 & 2.2 \\
& MAE 5 min $40^{\circ} \mathrm{C}$ & 76.7 & 2.1 \\
& Soaking $10 \mathrm{~s} 40^{\circ} \mathrm{C}$ & 12.0 & 0.4 \\
\hline
\end{tabular}




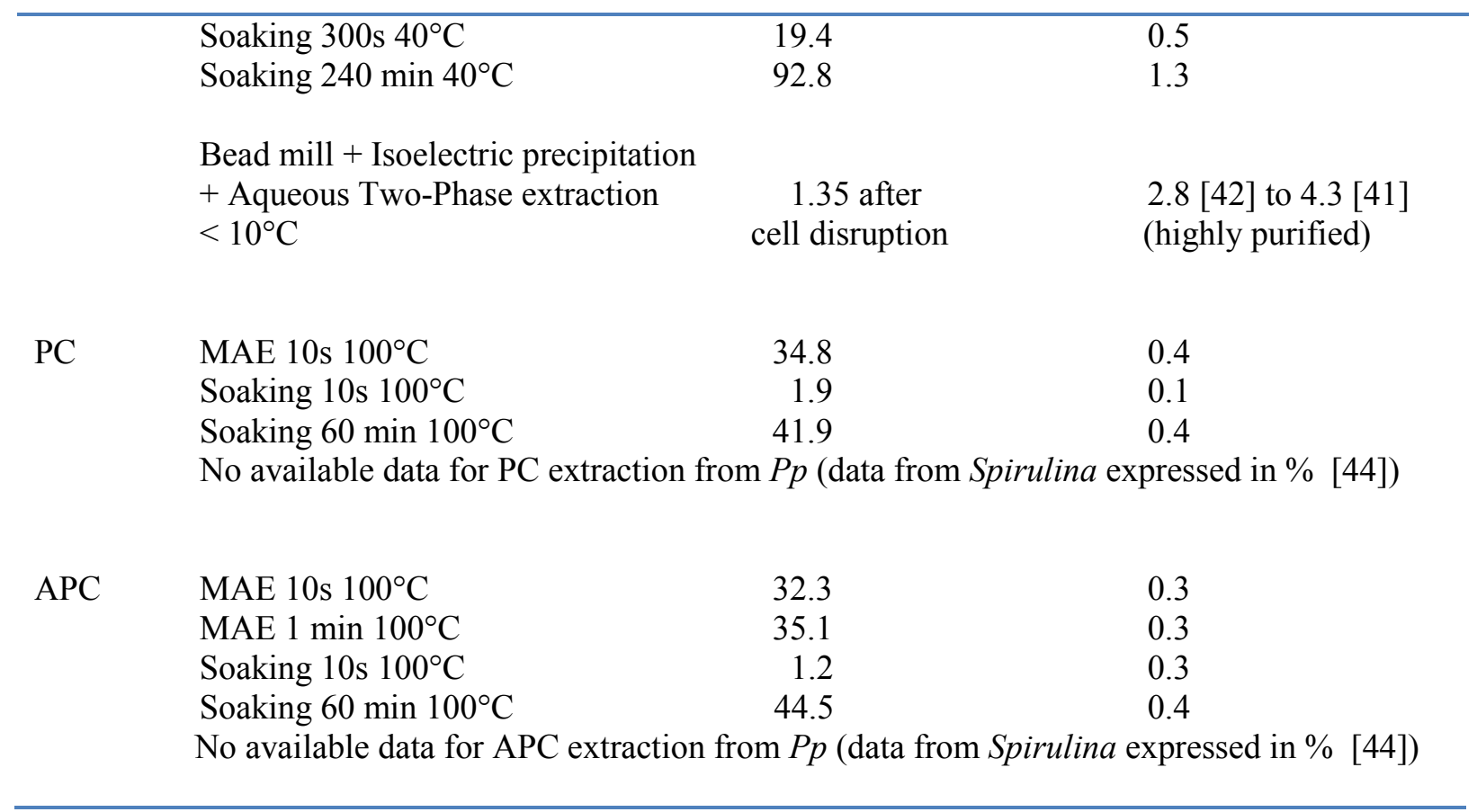

\subsection{Optimization of a two-steps MAE process to successively extract PE, PC and APC with high yields from the same $P p$ sample}

The best extraction sequence was defined as a first MAE $10 \mathrm{~s}$ at $40^{\circ} \mathrm{C}$ allowing the PE extraction with a selective extraction yield of $84.1 \%$, followed by a second MAE $30 \mathrm{~s}$ at $100^{\circ} \mathrm{C}$ on the remaining pellet, allowing the PC extraction with a selective extraction yield of $29.5 \%$ and APC extraction with a selective extraction yield of $31.1 \%$. One centrifugation step was necessary to collect the concentrated PBP solutions after each microwave irradiation. Soaking allowed to obtain high selective extraction yields but the whole performance of the soaking process was very limited by the total extraction time ( 270 min against $40 \mathrm{~s}$ in MAE).

\subsection{Absorbance and fluorescence properties of MAE extracted PBP}

MAE extracted PBP using the optimized protocols were stored at $4{ }^{\circ} \mathrm{C}$ in water solutions and their absorbance and fluorescence were recorded daily to check that their properties and stability were not altered by the MAE treatment. No major absorbance variation was recorded for the 3 PBP for up to 15 days for PE and 6 months for PC and APC (Figure 6.), demonstrating the stability of PBP absorption properties after MAE and their possible storage at $4{ }^{\circ} \mathrm{C}$ without important absorbance intensity fade out. In a same way, no fluorescence fade out was observed during a cold storage of PC for more than 2 months while PE and APC fluorescence progressively lost 30\% intensity in 75 days (Figure 6.). These data are coherent with a previous study indicating a good stability of absorbance and fluorescence properties of $\mathrm{PE}$, in a broad range of $\mathrm{pH}(4.0-10.0)$ for 25 days at room temperature, while PC and APC are more sensitive to thermal denaturation [45]. 

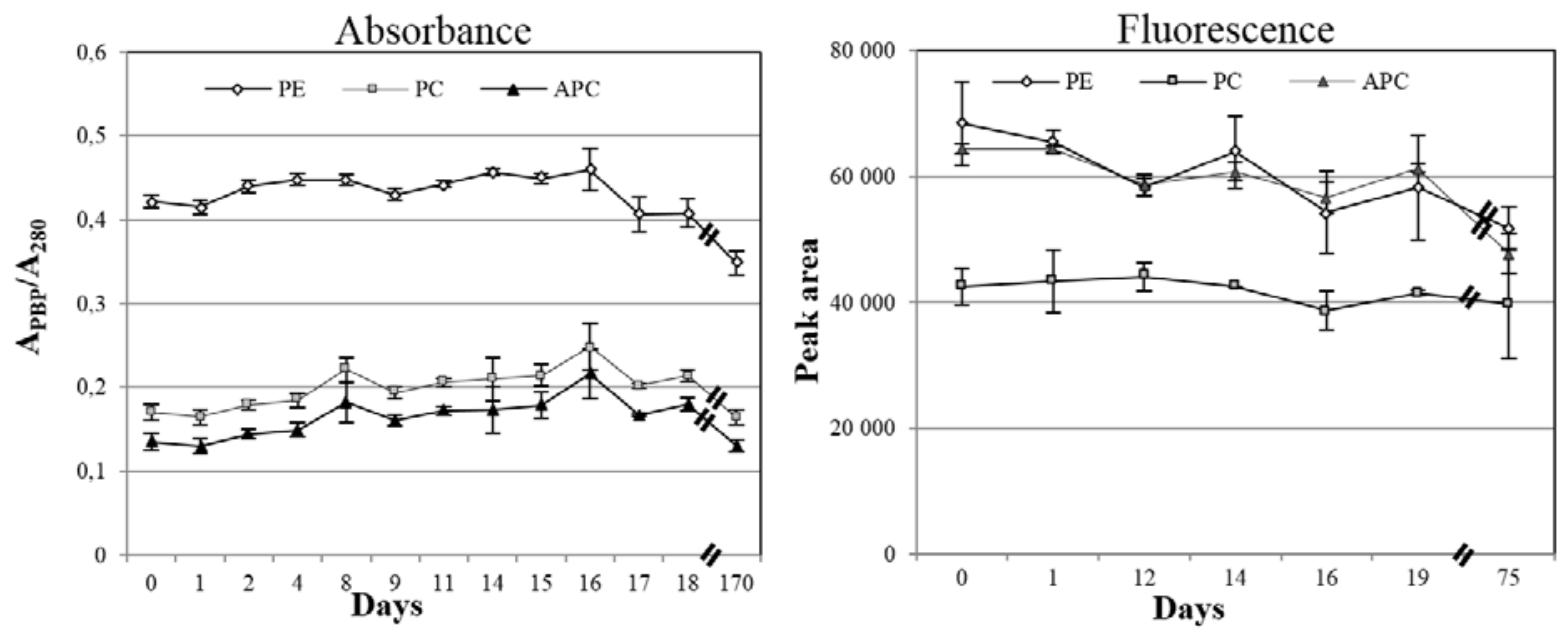

Figure 6. Absorbance and fluorescence of MAE extracted PBP. MAE extracted PBP were kept at $4^{\circ} \mathrm{C}$ in obscurity and their absorption and fluorescence properties were measured over several weeks after the microwave treatment.

\section{Molecular weight of MAE extracted PBP}

Standard PE gave a major red band at $16 \mathrm{KDa}$ that was identified as a mix of $\alpha$ and $\beta$ subunits [1] (Figure 7.). No band corresponding to an $\alpha \beta$ subcomplex was observed, suggesting that free $\alpha \beta$ protomers disassembled during PE purification. As the SDS-PAGE was performed without $\beta$-mercaptoethanol, it also demonstrated that no disulfide bridge linked the $\alpha$ and $\beta$ subunits to form $\alpha \beta$ protomers. The bands observed at 64, 132 and $155 \mathrm{Kda}$ may respectively correspond to $(\alpha \beta)_{2},(\alpha \beta)_{3} \gamma$ and $(\alpha \beta)_{4} \gamma$ subcomplexes [1]. The $P p$ MAE extract at $40^{\circ} \mathrm{C}$ contained a major red band at $136 \mathrm{KDa}$ that could correspond to an $(\alpha \beta)_{3} \gamma$ subcomplex of $\mathrm{PE}$ subunits, and two minor bands at $15 \mathrm{KDa}(\alpha$ and $\beta$ subunits) and $34 \mathrm{KDa}(\alpha \beta$ subcomplex or less probably $\gamma$ subunit) [1]. Standard PC, APC and MAE extracts at $100^{\circ} \mathrm{C}$ for $30 \mathrm{~s}$ and $60 \mathrm{~s}$ gave bands at 12-15 KDa corresponding to the PC and APC $\alpha$ and $\beta$ subunits [2] (Figure 7.). 


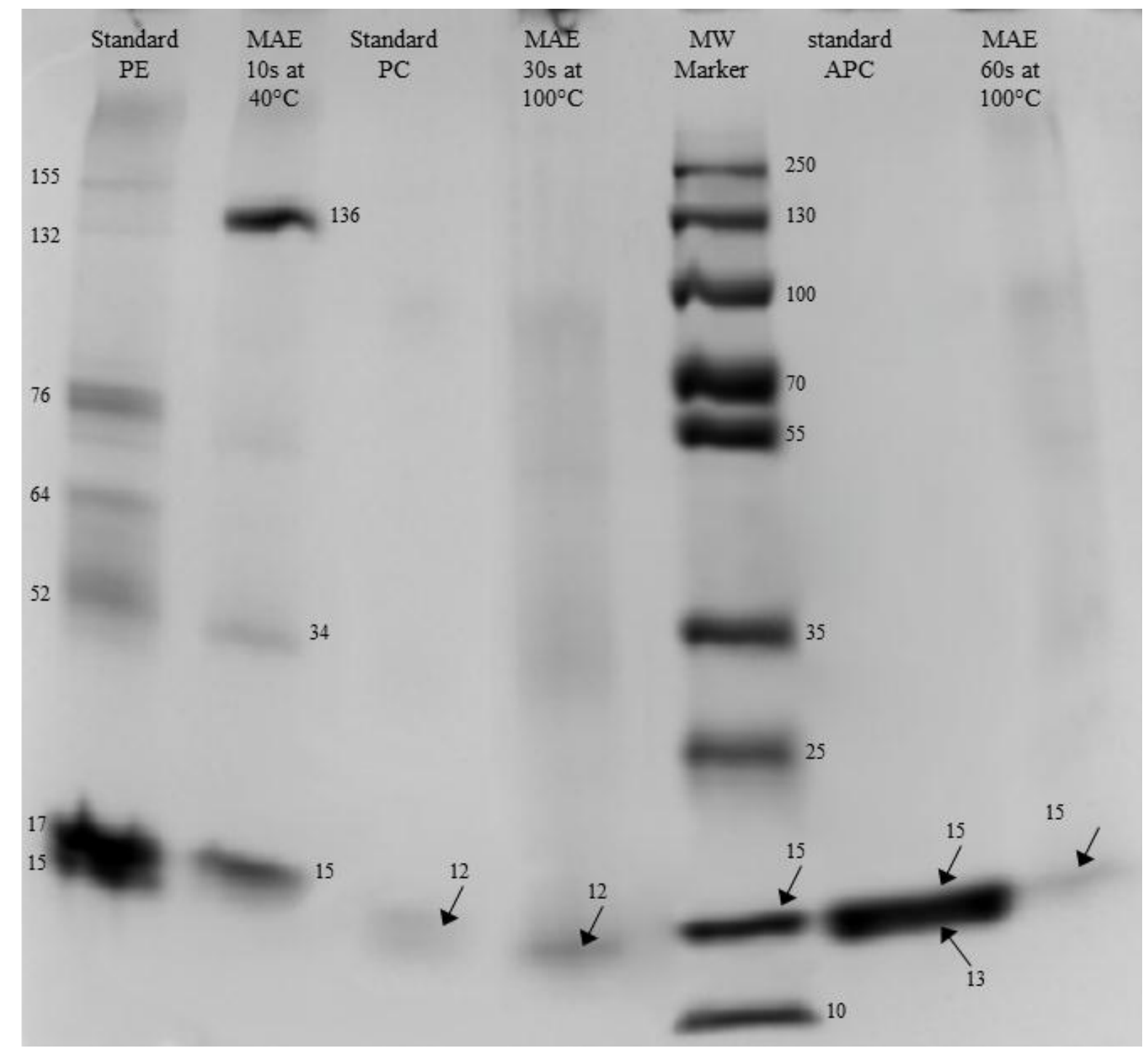

Figure 7. SDS-PAGE electrophoretic pattern of MAE extracted PBP and PBP standards. Molecular weights are expressed in KDa.

\section{Discussion}

We describe here the successful MAE extraction and pre-purification of phycobiliproteins from $P p$. MAE combined the qualities of a powerful pigment extraction process: rapidity, easiness, low cost, eco-efficiency, reproducibility, high extraction yields, possibility to selectively extract one PBP, possibility to couple the extraction process with a purification process such as gel permeation, and possibility to work in controlled conditions to limit the thermal degradation of PBP and conserve the spectroscopic qualities of the extracted pigments for several months. We had previously demonstrated that MAE was very efficient to extract pigments from frustulated microalgae, and we show here that it also presents a high interest to get access to pigments deeply buried in thylakoid membranes of species synthesizing a thick exopolysaccharidic cell wall. Compared to soaking, the use of microwaves accelerated pigments extraction kinetics up to 1080 fold, and improved pigment purity up to 3.8 fold before coupling to the purification step. Microwave heating offered the advantage of delivering an instantaneous and homogeneous temperature in the medium, as no heat transfer was required to heat the cells located in the center of the tube. Moreover, MAE allowed a fast and efficient PBP extraction without the need of high pressures, enzymes 
(lysozyme, xylanase), salts, toxic solvents, mechanical grinding or sonication. Consequently, limiting the steps number during the extraction process improves the final extraction yields and avoids time-consuming and fastidious protocols. According to the wide range of applications of PBP, and to their economic interest, the development of microwaves pilot units and industrial microwaves reactors should be considered to extract them at industrial scale. Indeed, PBP represent 28 to $68 \%$ of the total $P p$ soluble proteins (2.7 to $9.1 \mathrm{pg}$ PBP / $P p$ cell), and their expression can be increased by decreasing irradiance during the microalgae growth [33]. PE is the major PBP in $P p$, representing about $75 \%$ of the total PBP massic content, while PC and APC account together for $25 \%$. Beyond its utility for PBP extraction, this study opens the way for further MAE developments to extract thermosensitive molecules from various marine microalgae species, including those containing a thick exopolysaccharidic cell wall.

\section{Acknowledgements}

This research was financially supported by the French cancer league (Comité 17 de la Ligue Nationale contre le Cancer), European FEDER funds n³4755-2011 (ALG post-doctoral fellowship) and CPER "Contrats de Projet Etat-Région : Poitou-Charentes" funds (Project "Extraction of anticancer pigments from marine microalgae"). We are grateful to the PoitouCharentes region for $\mathrm{CJ}$ 's $\mathrm{PhD}$ grant. We also thank the "Cancéropôle Grand Ouest, axe Valorisation des produits de la mer en cancérologie" and Dr Hélène Montanié, Dr Isabelle Lanneluc and Dr Matthieu Garnier for scientific assistance.

\section{References}

1. Roy, S., Llewellyn, C., Skartstad Egeland, E., \& Johnsen, G. (Eds.). (2011). Phytoplankton Pigments: Characterization, Chemotaxonomy and Applications in Oceanography. Cambridge University Press. Retrieved from http://books.google.com/books?id=K_2AJHmdvxgC\&pgis $=1$

2. Redlinger, T., \& Gantt, E. (1981). Phycobilisome Structure of Porphyridium cruentum: Polypeptide composition. Plant physiology, 68(6), 1375-9. Retrieved from http://www.pubmedcentral.nih.gov/articlerender.fcgi?artid=426106\&tool=pmcentrez\&re ndertype $=$ abstract

3. Sidler, W. (1994). Phycobilisome and phycobiliprotein structures. In D. Bryant (Ed.), The Molecular Biology of Cyanobacteria (pp. 139-216). Springer Netherlands.

4. Dufossé, L., Galaup, P., Yaron, A., Arad, S. M., Blanc, P., Chidambara Murthy, K. N., \& Ravishankar, G. A. (2005). Microorganisms and microalgae as sources of pigments for food use: a scientific oddity or an industrial reality? Trends in Food Science \& Technology, 16(9), 389-406. doi:10.1016/j.tifs.2005.02.006

5. Kuddus, M., Singh, P., Thomas, G., \& Al-Hazimi, A. (2013). Recent developments in production and biotechnological applications of C-phycocyanin. BioMed research international, 2013, 742859. doi:10.1155/2013/742859 
6. Benedetti, S., Benvenuti, F., Scoglio, S., \& Canestrari, F. (2010). Oxygen radical absorbance capacity of phycocyanin and phycocyanobilin from the food supplement Aphanizomenon flos-aquae. Journal of medicinal food, 13(1), 223-7. doi:10.1089/jmf.2008.0257

7. UNESCO. (1997). Phytoplankton Pigments in Oceanography: Guidelines to Modern Methods. (S. Jeffrey, R. Mantoura, \& S. Wright, Eds.).

8. Eriksen, N. T. (2008). Production of phycocyanin--a pigment with applications in biology, biotechnology, foods and medicine. Applied microbiology and biotechnology, 80(1), 114. doi:10.1007/s00253-008-1542-y

9. Thangam, R., Suresh, V., Asenath Princy, W., Rajkumar, M., SenthilKumar, N., Gunasekaran, P., ... Kannan, S. (2013). C-Phycocyanin from Oscillatoria tenuis exhibited an antioxidant and in vitro antiproliferative activity through induction of apoptosis and G0/G1 cell cycle arrest. Food Chemistry, 140(1), 262-272. Retrieved from http://www.sciencedirect.com/science/article/pii/S0308814613002203

10. Gantar, M., Dhandayuthapani, S., \& Rathinavelu, A. (2012). Phycocyanin induces apoptosis and enhances the effect of topotecan on prostate cell line LNCaP. Journal of medicinal food, 15(12), 1091-5. doi:10.1089/jmf.2012.0123

11. Wu, L.-C., Lin, Y.-Y., Yang, S.-Y., Weng, Y.-T., \& Tsai, Y.-T. (2011). Antimelanogenic effect of c-phycocyanin through modulation of tyrosinase expression by upregulation of ERK and downregulation of p38 MAPK signaling pathways. Journal of biomedical science, 18 , 74. doi:10.1186/1423-0127-18-74

12. Nishanth, R. P., Ramakrishna, B. S., Jyotsna, R. G., Roy, K. R., Reddy, G. V, Reddy, P. K., \& Reddanna, P. (2010). C-Phycocyanin inhibits MDR1 through reactive oxygen species and cyclooxygenase-2 mediated pathways in human hepatocellular carcinoma cell line. European journal of pharmacology, 649(1-3), 74-83.

doi:10.1016/j.ejphar.2010.09.011

13. Pardhasaradhi, B. V. V, Ali, A. M., Kumari, A. L., Reddanna, P., \& Khar, A. (2003). Phycocyanin-mediated apoptosis in AK-5 tumor cells involves down-regulation of Bcl-2 and generation of ROS. Molecular cancer therapeutics, 2(11), 1165-70. Retrieved from http://www.ncbi.nlm.nih.gov/pubmed/14617790

14. Dumay, J., Clément, N., Morançais, M., \& Fleurence, J. (2013). Optimization of hydrolysis conditions of Palmaria palmata to enhance R-phycoerythrin extraction. Bioresource Technology, 131, 21-27. Retrieved from http://www.sciencedirect.com/science/article/pii/S0960852412020044

15. Sørensen, L., Hantke, A., \& Eriksen, N. T. (2013). Purification of the photosynthetic pigment C-phycocyanin from heterotrophic Galdieria sulphuraria. Journal of the science of food and agriculture, 93(12), 2933-8. doi:10.1002/jsfa.6116

16. Patil, G., \& Raghavarao, K. S. M. S. (2007). Aqueous two phase extraction for purification of C-phycocyanin. Biochemical Engineering Journal, 34(2), 156-164. Retrieved from http://www.sciencedirect.com/science/article/pii/S1369703X06003652 
17. Ramos, A., Acién, F. G., Fernández-Sevilla, J. M., González, C. V, \& Bermejo, R. (2011). Development of a process for large-scale purification of C-phycocyanin from Synechocystis aquatilis using expanded bed adsorption chromatography. Journal of chromatography. B, Analytical technologies in the biomedical and life sciences, 879(78), 511-9. doi:10.1016/j.jchromb.2011.01.013

18. Bermejo, R., Acién, F. G., Ibáñez, M. J., Fernández, J. M., Molina, E., \& Alvarez-Pez, J. M. (2003). Preparative purification of B-phycoerythrin from the microalga Porphyridium cruentum by expanded-bed adsorption chromatography. Journal of chromatography. B, Analytical technologies in the biomedical and life sciences, 790(1-2), 317-25. Retrieved from http://www.ncbi.nlm.nih.gov/pubmed/12767340

19. Soni, B., Trivedi, U., \& Madamwar, D. (2008). A novel method of single step hydrophobic interaction chromatography for the purification of phycocyanin from Phormidium fragile and its characterization for antioxidant property. Bioresource technology, 99(1), 188-94. doi:10.1016/j.biortech.2006.11.010

20. Moraes, C. C., \& Kalil, S. J. (2009). Strategy for a protein purification design using Cphycocyanin extract. Bioresource technology, 100(21), 5312-7. doi:10.1016/j.biortech.2009.05.026

21. Pasquet, V., Chérouvrier, J.-R., Farhat, F., Thiéry, V., Piot, J.-M., Bérard, J.-B., ... Picot, L. (2011). Study on the microalgal pigments extraction process: Performance of microwave assisted extraction. Process Biochemistry, 46(1), 59-67. doi:10.1016/j.procbio.2010.07.009

22. Choi, S.-K., Kim, J.-H., Park, Y.-S., Kim, Y.-J., \& Chang, H.-I. (2007). An efficient method for the extraction of astaxanthin from the red yeast Xanthophyllomyces dendrorhous. Journal of microbiology and biotechnology, 17(5), 847-52. Retrieved from http://www.ncbi.nlm.nih.gov/pubmed/18051308

23. Kadam, S. U., Tiwari, B. K., \& O’Donnell, C. P. (2013). Application of novel extraction technologies for bioactives from marine algae. Journal of agricultural and food chemistry, 61(20), 4667-75. doi:10.1021/jf400819p

24. Destandau, E., Michel, T., \& Elfakir, C. (2013). Microwave-assisted extraction. In M. A. Rostagno \& J. M. Prado (Eds.), Natural Product Extraction : Principles and Applications (pp. 157-195). Retrieved from https://www.google.fr/search?q=microwave+assisted+extraction+industrial\&oq=microw ave + assisted + extraction + industrial\&aqs $=$ chrome..69i57.12099j0j8\&sourceid $=$ chrome\&e $\mathrm{s} \_\mathrm{sm}=93 \& \mathrm{ie}=\mathrm{UTF}-8 \# \mathrm{q}=$ microwave + assisted + extraction + industrial

25. Mandal. (2007, January 1). Microwave assisted extraction - An innovative and promising extraction tool for medicinal plant research. Pharmacognosy Reviews. Medknow Publications. Retrieved from http://www.phcogrev.com/article.asp?issn=09737847; year $=2007$; volume $=1 ;$ issue $=1 ;$ spage $=7$; epage $=18$; aulast $=$ Mandal; type $=0$

26. Shin, S., Lee, A., Lee, S., Lee, K., Kwon, J., Yoon, M. Y., ... Kim, J. (2010). Microwaveassisted extraction of human hair proteins. Analytical biochemistry, 407(2), 281-3. doi:10.1016/j.ab.2010.08.021 
27. Moreira, M. M., Morais, S., Barros, A. A., Delerue-Matos, C., \& Guido, L. F. (2012). A novel application of microwave-assisted extraction of polyphenols from brewer's spent grain with HPLC-DAD-MS analysis. Analytical and bioanalytical chemistry, 403(4), 1019-29. doi:10.1007/s00216-011-5703-y

28. Wang, J.-X., Xiao, X.-H., \& Li, G.-K. (2008). Study of vacuum microwave-assisted extraction of polyphenolic compounds and pigment from Chinese herbs. Journal of chromatography. A, 1198-1199, 45-53. doi:10.1016/j.chroma.2008.05.045

29. Li, D.-C., \& Jiang, J.-G. (2010). Optimization of the microwave-assisted extraction conditions of tea polyphenols from green tea. International journal of food sciences and nutrition, 61(8), 837-45. doi:10.3109/09637486.2010.489508

30. Delazar, A., Nahar, L., Hamedeyazdan, S., \& Sarker, S. D. (2012). Microwave-assisted extraction in natural products isolation. Methods in molecular biology (Clifton, N.J.), 864, 89-115. doi:10.1007/978-1-61779-624-1_5

31. Orio, L., Cravotto, G., Binello, A., Pignata, G., Nicola, S., \& Chemat, F. (2012). Hydrodistillation and in situ microwave-generated hydrodistillation of fresh and dried mint leaves: a comparison study. Journal of the science of food and agriculture, 92(15), 3085-90. doi:10.1002/jsfa.5730

32. Teo, C. C., Tan, S. N., Yong, J. W. H., Hew, C. S., \& Ong, E. S. (2009). Validation of green-solvent extraction combined with chromatographic chemical fingerprint to evaluate quality of Stevia rebaudiana Bertoni. Journal of separation science, 32(4), 61322. doi:10.1002/jssc.200800552

33. Jahn, W., Steinbiss, J., \& Zetsche, K. (1984). Light intensity adaptation of the phycobiliprotein content of the red alga Porphyridium. Planta, 161(6), 536-539. doi:10.1007/BF00407086

34. Patel, A. K., Laroche, C., Marcati, A., Ursu, A. V., Jubeau, S., Marchal, L., ... Michaud, P. (2013). Separation and fractionation of exopolysaccharides from Porphyridium cruentum. Bioresource technology, 145, 345-50. doi:10.1016/j.biortech.2012.12.038

35. Serive, B., Kaas, R., Bérard, J.-B., Pasquet, V., Picot, L., \& Cadoret, J.-P. (2012). Selection and optimisation of a method for efficient metabolites extraction from microalgae. Bioresource technology, 124, 311-20. doi:10.1016/j.biortech.2012.07.105

36. Walne, P. (1966). Experiments in the large-scale culture of the larvae of Ostrea edulis (L.). In Fisheries investigations series II. London: Her Majesty's stationery office. Pp. iii. 53. London.

37. Munier, M., Jubeau, S., Wijaya, A., Morançais, M., Dumay, J., Marchal, L., ... Fleurence, J. (2013). Physicochemical factors affecting the stability of two pigments: RPhycoerythrin of Grateloupia turuturu and B-Phycoerythrin of Porphyridium cruentum. Food Chemistry. Retrieved from http://www.sciencedirect.com/science/article/pii/S0308814613015628 
38. Bennett, A., \& Bogorad, L. (1973). Complementary chromatic adaptation in a filamentous blue-green alga. The Journal of cell biology, 58(2), 419-35. Retrieved from

http://www.pubmedcentral.nih.gov/articlerender.fcgi?artid=2109051\&tool=pmcentrez\&r endertype $=$ abstract

39. Bryant, D. A., Guglielmi, G., Marsac, N. T., Castets, A.-M., \& Cohen-Bazire, G. (1979). The structure of cyanobacterial phycobilisomes: a model. Archives of Microbiology, 123(2), 113-127. doi:10.1007/BF00446810

40. Bermejo Román, R., Alvárez-Pez, J. M., Acién Fernández, F. G., \& Molina Grima, E. (2002). Recovery of pure B-phycoerythrin from the microalga Porphyridium cruentum. Journal of biotechnology, 93(1), 73-85. Retrieved from http://www.ncbi.nlm.nih.gov/pubmed/11690696

41. Ruiz-Ruiz, F., Benavides, J., \& Rito-Palomares, M. (2013). Scaling-up of a Bphycoerythrin production and purification bioprocess involving aqueous two-phase systems: Practical experiences. Process Biochemistry, 48(4), 738-745. doi:10.1016/j.procbio.2013.02.010

42. Benavides, J., \& Rito-Palomares, M. (2005). Potential Aqueous Two-Phase Processes for the Primary Recovery of Colored Protein from Microbial Origin. Engineering in Life Sciences, 5(3), 259-266. doi:10.1002/elsc.200420073

43. Filly, A., Fernandez, X., Minuti, M., Visinoni, F., Cravotto, G., \& Chemat, F. (2014). Solvent-free microwave extraction of essential oil from aromatic herbs: from laboratory to pilot and industrial scale. Food chemistry, 150, 193-8.

doi:10.1016/j.foodchem.2013.10.139

44. Bermejo, R., Felipe, M. A., Talavera, E. M., \& Alvarez-Pez, J. M. (2006). Expanded Bed Adsorption Chromatography for Recovery of Phycocyanins from the Microalga Spirulina Platensis. Chromatographia, 63(1-2), 59-66. doi:10.1365/s10337-005-0702-9

45. González-Ramírez, E., Andújar-Sánchez, M., Ortiz-Salmerón, E., Bacarizo, J., Cuadri, C., Mazzuca-Sobczuk, T., ... Martínez-Rodríguez, S. (2014). Thermal and pH Stability of the B-Phycoerythrin from the Red Algae Porphyridium cruentum. Food Biophysics, 9(2), 184-192. doi:10.1007/s11483-014-9331-x 